three determinations agree within $7^{\circ}$ of the position R.A. $=90^{\circ}$, dec. $=-12^{\circ}$, and for Stream II. within $14^{\circ}$ of the position R.A. $=263^{\circ}$, dec. $=-60^{\circ}$ (Proc. Roy. Soc. Edinburgh, vol. xxviii., part iii., No. 13, p. 231, February).

Determination of the Errors of the Paris ObservaTORY RÉsEaUX.-In a paper communicated to the Paris Academy of Sciences, M. Jules Baillaud describes a novel method whereby he has determined the errors of the réseaux used in connection with the Carte du Ciel plates at the Paris Observatory. By this method the influences of variations of temperature and of deformation of the gelatin film during development are eliminated, and $M$. Baillaud. finds that the errors attain the value $3 \mu$, the variations between measures on several plates not exceeding $0.5 \mu$. This is of the same order of size as the grain of the plate used, and it would probably be possible to reduce the apparent discordance by using plates of a finer grain (Comptes rendus, No. 12, March 23, p. 6r6).

The Herschers' Nebulze.-No. 4, vol. ii., of the Rivista di Astronomia (Turin, April, p. 82) contains an article of especial interest and value by Madame Dorothea IsaacRoberts, who discusses the nebula discovered by the Herschels as photographed by the late Dr. Isaac Roberts. The author first gives a brief review of the history of nebulæ observations from the time that Galileo discovered the first true nebula in 1610 ; then follows an explanation of the classification of nebulæ made by Sir William Herschel, and of the code used by Sir John Herschel in his descriptions of nebulæ. A brjef description of the plates shown in the latter's memoir of 1833 is followed by a discussion of the groups of nebulous bodies as classified by Dr. Roberts. The paper concludes with a brief sketch of the lines which the author's discussion of Dr. Roberts's plates will follow, and is to be continued in the following number of the review.

Horizon and Prime-vertical Curves for Latitudes $+30^{\circ}$ To $+60^{\circ}$. - In these columns for January 30 (NATURE, No. I996, p. 302) we described briefly a useful sun and planet chart submitted for our inspection by Messrs. Carl Zeiss. The same firm has now sent us a transparent celluloid scale, devised by Herr H. H. Kritzinger, which, when used in conjunction with the charts, enables one to see at a glance the relative positions of the local horizon and prime vertical for any place between latitudes $30^{\circ}$ and $60^{\circ}$ north. This allows the approximate sidereal time of rising and setting of the stars, and of their transit through the prime vertical, to be found at once, and with no trouble beyond that involved in superposing two sets of lines. Messrs. Zeiss will be pleased to send copies of this new scale on receiving applications.

\section{EDUCATIONAL LEAKAGE.}

$T H E$ success of any system of technical instruction or higher education depends ultimately upon the preparatory education of the students in our technical schools and other institutions of higher education. The results hitherto obtained from the work of colleges and technical schools in this country have been discounted seriously by the inadequacy in the nature and supply of the education for boys of school age. Mr. V. A. Mundella, in an address delivered last year to the Association of Teachers in Technical Institutions, directed attention to the subject, and also by means of curves illustrating recent statistics demonstrated the serious leakage of children at twelve and thirteen years of age, who afterwards receive no education whatever.

The accompanying diagram shows the number of children at stated ages, and the grade of education, if any, they are receiving. Mr. Mundella states that there are in England and Wales, between the ages of eleven and twelve vears, 718,000 children, of whom 620,000 are in elementary schools, and at the outside 40,000 in public and private secondary schools. The curve $T$ shows the total number of children at each year of age up to twenty-one years, and the curve $A$ the total number of these children in elementary schools. The form of A shows strikingly the rapid decrease in school attendance between the thirteenth and fifteenth years. The curve $t$ exhibits the number of children surviving, at each year of age, who have attended an elementary school, and a comparison of this curve with those marked B, C, X, shows how little has been accomplished in the direction of continuing the education of the nation's children after the elementary school has been left. Curve $B$ illustrates the total number of children in science and art classes, $\mathrm{C}$ in evening continuation schools, $\mathrm{X}$ in secondary schools, and $U-a$ continuation of $X-$ in universities and university colleges. The curve $\mathrm{X}$ is based upon statistics published in 1898 , no later statistics being available. The curve $D$ represents the number of surviving

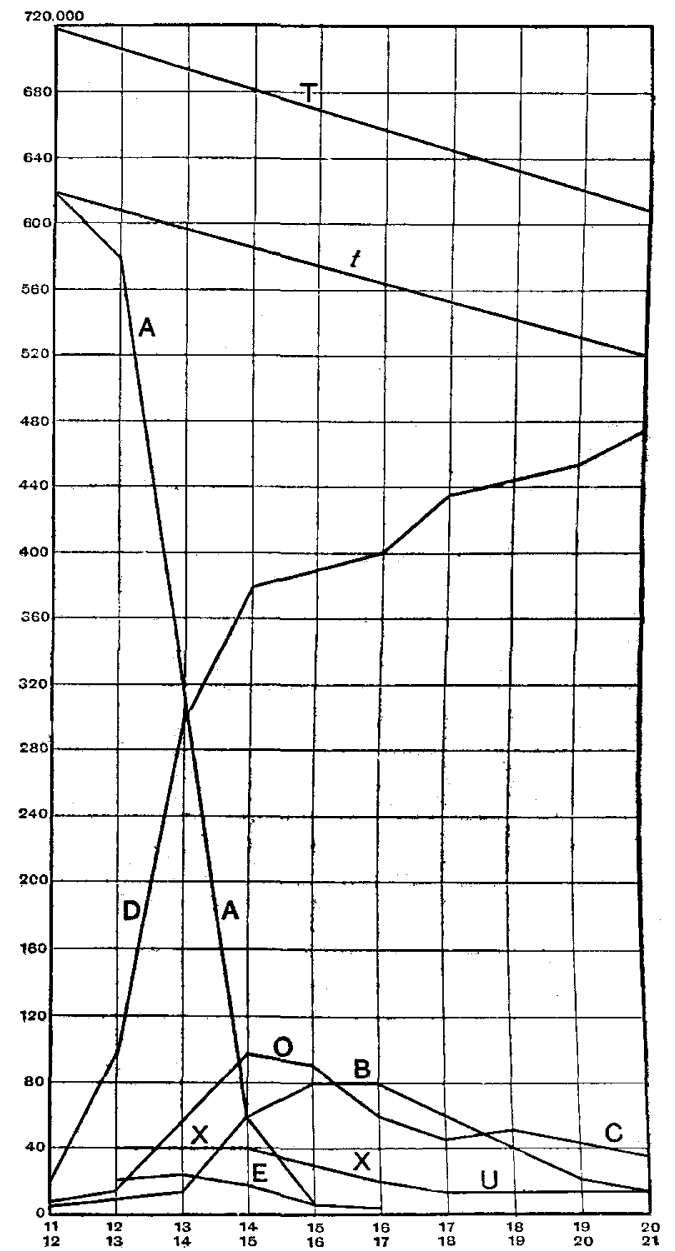

Diagram showing the number of young people in England and Wale between the ages of $I I$ and $2 I$, and the number receiving education in schools and colleges of various types.

children who have attended elementary schools, but are receiving no further organised education, and $E$ shows the total number of children at each age taking approved courses of instruction in State-aided secondary schools.

The facts embodied in this diagram demonstrate very clearly the need for strenuous national effort to insist upon children attending primary schools until they are fourteen years of age and abolish the present system of half-timers and other exemptions, to provide for continuation schools at which attendance shall be compulsory, and to establish secondary. schools which are really schools of a high educational type. Schools in which 80 per cent. of the pupils leave at fifteen years of age or under are better described as higher elementary schools than as secondary schools, under which title they are at present classified.

NG. 2009, VOL. Ti] 